\title{
BIOCONVERSION OF VARIOUS AGRO-INDUSTRIAL BYPRODUCTS INTO BIOETHANOL BY TWO LOCAL YEAST STRAINS USING STATIC CULTURE TECHNIQUE
}

\author{
EL TAYEB, T.S. ${ }^{1}$, HEMMAT M. ABDELHADY ${ }^{1}$, \\ E. A. SALEM ${ }^{2}$, EBTSAM Z. ABDEL-ALL ${ }^{3}$ \\ 1. Department of Agricultural Microbiology, Faculty of Agriculture, Ain Shams \\ University, Egypt. \\ 2. Central Laboratory for Agricultural Climate, Agricultural Research Center, \\ Ministry of Agriculture, Giza, Egypt. \\ 3. Department of Microbiology, Faculty of Science, Banha University, Egypt.
}

(Manuscript received 17 December 2015)

\begin{abstract}
$\mathrm{S}$

ome agro-industrial byproducts [sugar cane molasses (SM), corncobs waste $(\mathrm{CW})$, sugar cane bagasse (SB), sawdust (SD), sugar beet pulp (SBP) and fruit juice waste (FJW)] were used as substrates for bioethanol production by Clavispora Iusitaniae Gr45 and Saccharomyces cerevisiae B1 after 3 days incubation at $30^{\circ} \mathrm{C}$ in static batch culture. Different treatments of these materials as a sole carbon source were applied with or without nitrogen sources (yeast extract or ammonium sulfate). The highest bioethanol concentration when SM is used $\left(13.05 \mathrm{gl}^{-1}\right)$ was obtained by Sacch. cerevisiae at the treatments: [yeast fermentation medium (YFM) -glucose $+4 \% \mathrm{SM}$ ), (yeast extract + $6 \% \mathrm{SM})$ and $(10 \% \mathrm{SM})$, which represent about $10.6 \%$ increase comparing to YFM medium (control). The addition of acid CW hydrolyzate as the sole carbon source to YFM medium was the best of the CW treatments by Cl. Iusitaniae Gr45 which recorded the highest bioethanol concentration, productivity, yield and conversion coefficient being, $13.32 \mathrm{gl}^{-1}, 0.18 \mathrm{gl}^{-1} \mathrm{~h}^{-1}, 26.64 \%$ and $26.65 \%$; respectively. These figures were increased to $15.8 \mathrm{gl}^{-1}, 0.22 \mathrm{gl}^{-1} \mathrm{~h}^{-1}$, $31.6 \%$ and $35.9 \%$, respectively, on YFM medium containing acid SB hydrolyzate as the sole carbon source. All acid SD hydrolyzate treatments increased bioethanol production by $\mathrm{Cl}$. Iusitaniae $\mathrm{Gr} 45$ and decreased it by Sacch. cerevisiae B1. The highest bioethanol production obtained on SD was on SD hydrolyzate containing yeast extract followed by SD hydrolyzate only and SD hydrolyzate containing ammonium sulfate being 16.5, 13.76 and $13.54 \mathrm{gl}^{-1}$; respectively. Using SBP as sole carbon source added to YFM medium decreased significantly the growth and bioethanol production by both strains. Generally, FJW was the best carbon source in YFM medium which increased bioethanol production to about $68 \%$ and $38 \%$ by Sacch. cerevisiae B1 and Cl. lusitaniae Gr45; respectively using static culture technique.
\end{abstract}

\section{INTRODUCTION}

In recent years, Growing attention has been paid to the conversion of biomass into ethanol, a clean liquid fuel, that considered the alternative to fossil fuels which may be depleted in the next years. Converting lignocellulosic biomass into 
fermentable sugars is a major bottleneck for lignocellulose-derived bioethanol production. Plant biomass or lignocellulosic biomass, i. e. agricultural residues, agroindustrial byproducts and energy crops is evaluated worldwide as a potential feedstock for the sustainable production of bioenergy due to its abundance, availability and renewability. On the other hand, using agricultural residues in the production of the biofuel reduce burning of these residues which usually happened by farmers for clearing the field, which subsequently reduce the air pollution and emission of greenhouse gases. (Phitsuwan et al., 2013).

The selection of lignocellulosic crops likely depends on quantity and agronomic considerations including seasons, environment, and regional geography. In Brazil, ethanol from sugar cane has been utilized in the transportation sector since 1975 (Yan et al., 2013). In the USA, switchgrass is the leading dedicated energy crop that has been selected for ethanol production (Keshwani and cheng 2009).

Molasses, the byproduct of the sugar-processing and other intermediates from sugar cane processing are very good raw materials for ethanol production due to their high content of fermentable sugars, which can be directly used for fermentation without any modification (Vučurović and Razmovski, 2012). Rodriguez et al. (2010) mentioned that grape pomace could be an important agro-industrial waste to be transformed into bioethanol.

Some yeasts use alcoholic fermentation for respiration. Rao et al. (2008) isolated a total of 374 yeasts from a variety of rotten fruits and barks of trees. Out of these, 27 yeast strains were able to assimilate xylose and produce $0.12-0.38 \mathrm{~g}$ of ethanol per gram of xylose. Saccharomyces cerevisiae is the most widely used ethanol producing microorganism. It has attracted considerable attention in recent years for the production of bioethanol from agricultural wastes owing to its higher tolerance to both ethanol and inhibitors present in hydrolysates of lignocellulosic materials (Bettiga et al., 2009).

Freer and Greene (1990) demonstrated that Clavispora lusitaniae NRRL Y-5394 and Candida wickerhamii NRRL Y-2563 had faster initial rates of ethanol production from cellobiose than did the other cellobiose-fermenting yeasts tested. Both yeasts are capable of rapidly fermenting cellobiosesubstrate. Utilization studies showed that Cl. Iusitaniae could ferment only glucose and cellobiose, while C. wickerhamii fermented glucose, cellobiose, and cellodextrins.

The scope of this work was to evaluate the potentiality of using different agroindustrial byproducts as raw materials for the production of bioethanol by fermentation using locally isolated bioethanol producing yeasts Clavispora lusitaniae Gr45 and Saccharomyces cerevisiae B1. 


\section{MATERIALS AND METHODS}

\section{Yeasts used}

Stock yeast culture (Saccharomyces cerevisiae B1 and Clavispora lusitaniae Gr 45) slants were obtained kindly from Department of Microbiology, Faculty of Agriculture, Ain Shams Univ. maintained at $5^{\circ} \mathrm{C}$ on a preservation media after incubation at $30^{\circ} \mathrm{C}$ for $48-72 \mathrm{~h}$. Standard inoculum was prepared by inoculation of conical flask $(250 \mathrm{ml})$ containing $100 \mathrm{ml}$ of yeast extract peptone medium (YEPM) with a loop of the tested culture. Then, incubated at $30^{\circ} \mathrm{C}$ for $24 \mathrm{hrs}$. The content of this flask was used as standard inoculum (O.D, 1.3 and 0.9 for Sacch. cerevisiae B1 and Cl. Iusitaniae $\mathrm{Gr} 45$, respectively) for static flask culture experiments.

\section{Media used}

-Yeast extract peptone medium (YEPM) (Liang et al., 2008), which has the following composition (g/l): glucose (20), yeast extract (10) peptone (20) agar (20) and completed with distilled water to $1000 \mathrm{ml}$ ( $\mathrm{pH}$ was adjusted to 6.0). This media was used for culture maintainance as preservation media at $5^{\circ} \mathrm{C}$.

-Yeast fermentation mediaum (YFM) (Banat and Marchant, 1995) which has the following composition (g/l): $\mathrm{KH}_{2} \mathrm{PO}_{4}(2.0)$, $\mathrm{MgSO}_{4} .7 \mathrm{H}_{2} \mathrm{O}(1.0),\left(\mathrm{NH}_{4}\right)_{2} \mathrm{SO}_{4}(2.0)$, Yeast extract (0.5), $\mathrm{MnSO}_{4}(0.1)$, glucose (50) and completed with distilled water to $1000 \mathrm{ml}$ ( $\mathrm{pH}$ was adjusted to 6.0). This media was used in all experiments with amount of $100 \mathrm{ml}$ in $250 \mathrm{ml}$ Erlenmeyer flasks.

\section{Agro-industrial byproducts}

Some local agro-industrial byproducts such as corncob waste (CW), sugar cane bagasse (SB), sawdust (SD), sugar beet pulp (SBP) as well as sugar cane molasses (SM) or fruit juice waste (FJW) were used as a carbon source either alone or in combination with other constituents of YFM medium (Banat and Marchant, 1995).

\section{Acid hydrolysis of agro-industrial byproducts}

Diluted acid hydrolysis of CW, SB, SD, SBP, using sulphuric acid (2.0\%) was performed in the autoclave at $120^{\circ} \mathrm{C}$ for $30 \mathrm{~min}$. in $2 \mathrm{~L}$ flasks. The solid: liquid final ratio was $5 \%$. After hydrolysis process, solid materials were removed by filtration. The resulting hydrolyzate was neutralized with calcium carbonate then centrifuged. The filtrates were kept in refrigerator at $5-7^{\circ} \mathrm{C}$ till use. Each acidic hydrolyzate was used alone or added to YFM medium as a sole carbon source or supplemented with nitrogen source (ammonium sulfate or yeast extract). 


\section{Sugar cane molasses}

Five concentrations of sugar cane molasses (SM) from 2 to $10 \%$ with $2 \%$ intervals were tested in order to detect the best treatment at the optimum SM concentration for maximum bioethanol production by the tested yeast strains. These SM treatments were using different SM concentrations alone as whole medium, adding to YFM medium as a sole carbon source and adding to nitrogen source only (ammonium sulfate or yeast extract).

\section{Fruit juice waste}

Different concentrations of FJW ranging from 80 to $150 \mathrm{mll}^{-1}$ were used. This experiment was designed to determine the suitable fruit juice waste (FJW) concentration which gives the highest bioethanol production by the tested yeast strains.

\section{Chemical determinations}

Total nitrogen (Jackson, 1973) and total sugar (Flood and Preistly, 1973) were determined in SM, acidic hydrolysis of cellulosic agro-industrial byproducts (SD, SB, CW and SBP) and FJW. Residual glucose in fermented culture was determined with glucose kits according to by method of Young and Friedman (2001). Bioethanol in fermented culture was determined colormetrically according to the method of Lau and Luk (1994). Yield of bioethanol and productivity were calculated according to Gamal et al. (1991) using the following equations:

$$
\begin{gathered}
\text { Yield }(\%)=\underline{\text { Bioethanol produced }\left(\mathrm{gl}^{-1}\right)} \times 100 \\
\text { Original sugar concentration }\left(\mathrm{gl}^{-1}\right) \\
\text { Productivity }\left(\mathrm{gl}^{-1} \mathrm{~h}^{-1}\right)=\frac{\text { Bioethanol produced }\left(\left.\mathrm{gl}\right|^{-1}\right)}{\text { Fermentation time }(\mathrm{h})}
\end{gathered}
$$

Conversion coefficient of bioethanol was calculated according to Ramadan et al. (1985) as following :

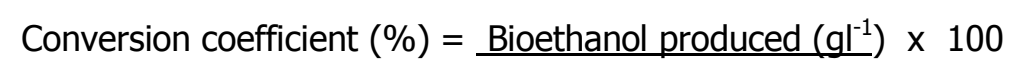

$$
\text { Utilized sugar }\left(\mathrm{gl}^{-1}\right)
$$

\section{Statistical analysis}

The collected data were statistically analyzed using SPSS computer analysis program (Forster, 2001). 


\section{RESULTS AND DISCUSSION}

Although intensive activity toward the development of bioethanol production is taking place, commercial products are few and costly. One of the important issues related to bioethanol production is the reduction of production costs. Bioconversion of raw materials to available fermentable sugars is probably the most cost effective and environment friendly procedure for raw materials utilization. Therefore, six agroindustrial byproducts, i.e. sugar cane molasses, corncob waste, sugar cane bagasse, sawdust, sugar beet pulp and fruit juice waste were used for bioethanol production by the most efficient bioethanol producing strains Cl. Iusitaniae Gr45. and Sacch. cerevisiae B1 in static batch culture. Most lignocellulosic materials need to be pretreated before used as substrate for bioethanol production. Dilute acid hydrolysis has been successfully developed for pretreatment of different lignocellulosic materials. Dilute sulphuric acid has been the most commonly used so far for converting cellulosic materials into fermentable sugars with high reaction rates, especially as it is a low cost technology (Jeffries and Jin, 2000).

Different treatments of these agro-industrial byproducts were applied as whole medium with or without nitrogen sources (yeast extract or ammonium sulfate) and as a sole carbon source on YFM medium. The used agro-industrial byproducts were varied in sugar and nitrogen content as presented in Table 1. Data revealed that all tested materials were rich in sugar content which ranged from 35.42 (FJW) to $48.3 \%$ (SM). While, total nitrogen was ranged from 0.24 (SD) to $2.5 \%$ (FJW).

\section{Sugar cane molasses (SM)}

Sugar cane molasses (SM), is a byproduct of sugar industry, contains high sugar concentration and other metals necessary for the fermentation process and is inexpensive. SM has been successfully used for fermentative production of bioethanol. Several microorganisms, including the well-known yeast bioethanol producer, Sacch. cerevisiae. In this investigation, SM in different concentrations ranged from 2 to $10 \%$ SM were used for bioethanol production by Cl. Iusitaniae Gr45 or Sacch. cerevisiae B1. Results of different SM treatments were tabulated in Tables 2 and 3. The results indicated that increasing the SM concentrations led to increase the bioethanol production at all treatments and recorded the highest figure by $\mathrm{Cl}$. lusitaniae $\mathrm{Gr} 45$ at $10 \%$ SM (Table 2). All SM treatments at $10 \%$ concentration gave bioethanol concentration lower than YFM medium $\left(12.45 \mathrm{gl}^{-1}\right)$. These values were 9.8, 8.33, 8.12 and $7.0 \mathrm{gl}^{-1}$ bioethanol for $10 \%$ SM in YFM medium as carbon source, added to yeast extract or ammonium sulfate and as whole medium, respectively. The corresponding figures of bioethanol productivity were $0.13,0.11,0.11$ and $0.09 \mathrm{gl}^{-1} \mathrm{~h}^{-1}$, respectively. 
This may was in agreement with obtained results of Takeshige and Ouchi (1995). They found that bioethanol production by yeast strain, $X_{2} 180-1 B$, was less than half by alcohol yeast, YOY655 in a SM medium containing $30 \%$ sugars, although both strains produced approximately the same amount of bioethanol in a nutrition medium with the same sugar content. They added that the poor fermentation of $X_{2} 180-1 B$ is not because of its weak fermentation capacity, arises from its susceptibility to some factors in SM other than sugars. Moreover, no significant difference was observed between SM concentrations of $4 \%$ and $6 \%$ used as whole medium or that added to yeast extract on the bioethanol production. Data also clearly show that using $10 \%$ SM was the most appropriate concentration for highest bioethanol production by Sacch. cerevisiae B1 if molasses were used without any additives, being $13.05 \mathrm{gl}^{-1}$ (Table 3). The highest bioethanol concentration being $13.05 \mathrm{gl}^{-1}$ was also obtained on SM added to YFM medium without glucose at the concentration of $4 \%$ and on the treatments of $6 \%$ SM containing yeast extract.

\section{Corncobs waste (CW)}

Corncobs waste (CW) has the potential to produce alcohol components as mentioned by (Reno et al., 2011). Corncobs wastes are produced with huge quantities all over the country. The discarding of these tons of wastes always considered a terrible problem. This is due to the expensive cost of transferring this waste and the pollution from discarding them by burning. In the trials for using this waste as substrate for bioethanol fermentation, data given in Table (4) revealed that YFM medium containing CW waste hydrolyzate as sole carbon source gave the highest bioethanol production (13.32 gl-1) among all other treatments, which increased about $6.98 \%$ comparing to control. In this treatment, the highest figures of bioethanol productivity, bioethanol yield and conversion coefficient being $0.18 \mathrm{gl}^{-1} \mathrm{~h}^{-1}, 26.64 \%$ and $26.65 \%$, respectively were obtained. On the contrary, by Sacch. cerevisiae B1 (Table 5), all treatments of CW hydrolyzate didn't enhance bioethanol production. Whereas, YFM complete medium (control) attained the highest bioethanol concentration $\left(11.5 \mathrm{gl}^{-1}\right)$. Also, it could be noticed that using $\mathrm{CW}$ hydrolyzate as a whole medium recorded the lowest bioethanol production by both strains. At all CW treatments, the growth of both strains was lower than attained by YFM medium. Ge et al. (2011) obtained 36.49 total reducing sugars $(\mathrm{g} / \mathrm{l})$ when treated corncob hydrolysis with $1 \%(\mathrm{v} / \mathrm{v})$ of sulfuric acid, and when the acid hydrolysate was detoxified with overliming plus activated charcoal, that yielded maximum productivity of $0.152 \mathrm{gl}^{-1} \mathrm{~h}^{-1}$ and bioethanol yield of $0.31 \mathrm{gg}^{-1}$. 


\section{Sugar cane bagasse (SB)}

Sugar cane bagasse (SB) is one of the cellulosic feedstock that used for bioethanol production. Different treatments to SB hydrolyzate were prepared as previously conducted. Data given in Tables 6 and 7 indicated to significant effect of SB treatments on the growth and bioethanol production by both tested strains. The highest bioethanol production was obtained by $\mathrm{Cl}$. Iusitaniae Gr45 on YFM medium containing the SB hydrolyzate as a sole carbon source. This treatment also recorded the highest bioethanol concentration, yield, productivity and conversion coefficient being $15.8 \mathrm{gl}^{-1}, 31.6 \%, 0.22 \mathrm{gl}^{-1} \mathrm{~h}^{-1}$ and $35.9 \%$, respectively. While Sacch. cerevisiae B1 on different SB treatments (Table 7) achieved lower bioethanol production than YFM medium. The lowest bioethanol concentrations were obtained by Sacch. cerevisiae $\mathrm{B} 1$ and $\mathrm{Cl}$. lusitaniae $\mathrm{Gr} 45$ at SB hydrolyzate as whole treatment being 2.97 and $6.5 \mathrm{gl}^{-1}$, respectively. In this respect, Gubicza et al. (2014) used dilute phosphoric acid and steam explosion as pretreatment for SB. This process has been successfully scaled-up to $80 \mathrm{~L}$ fermentations with yields as high as $0.27 \mathrm{gg}^{-1}$.

\section{Sawdust (SD)}

Sawdust (SD) can be used as a veritable resource for bioethanol production. Different treatments to SD were prepared as previously conducted. Data presented in Table 8 show that all treatments of SD hydrolyzate recorded by Cl. Iusitaniae Gr45 attained higher bioethanol production than YFM medium. The highest bioethanol production was obtained at SD hydrolyzate containing yeast extract followed by SD hydrolyzate only and SD hydrolyzate containing ammonium sulfate being 16.5, 13.76 and $13.54 \mathrm{gl}^{-1}$, respectively. At the first treatment bioethanol productivity, yield, conversion coefficient, were $0.23 \mathrm{gl}^{-1} \mathrm{~h}^{-1}, 33.0 \%$ and $33.0 \%$, respectively. On contrast, all SD treatments gave lower bioethanol production by Sacch. cerevisiae B1 than the control (YFM medium) (Table 9). The lowest values of bioethanol concentrations, productivity, yield and conversion coefficient were observed at SD hydrolyzate treatment followed by that containing ammonium sulfate and yeast extract. Moreover, the first treatment recorded the lowest growth of $\mathrm{Cl}$. Iusitaniae Gr45 and Sacch. cerevisiae B1 with decreased about (57.2\%) and (57.9\%) than control, respectively. The final pH range obtained by Sacch. cerevisiae B1 (4.8-4.9) was lower than that obtained by $C$. Iusitaniae Gr45 (5.52-6.65) at different treatments.

\section{Sugar beet pulp (SBP)}

Data given in Tables 10 and 11 show the bioethanol production by Cl. Iusitaniae Gr 45 and Sacch. cerevisiae B1 after three days incubation period on different 
treatments of acid beet waste (SBP) hydrolyzate. It could be noticed that most treatments of SBP hydrolyzates didn't enhance bioethanol production by both tested strains, but YFM complete medium (control) attained the highest bioethanol concentration. Addition of nitrogen source as $\left(\mathrm{NH}_{4}\right)_{2} \mathrm{SO}_{4}$ and yeast extract gave the highest bioethanol production by $\mathrm{Cl}$. Iusitaniae $\mathrm{Gr} 45$ and Sacch. cerevisiae B1 being 10.73 and $4.03 \mathrm{gl}^{-1}$ respectively. This result may coincide with what mentioned by Ergun and Mutlu (2000), they stated that there is a digestible nitrogen deficiency of sugar beet molasses, so, addition of ammonium phosphate, ammonium dihydrogen phosphate and ammonium sulfate are usually performed to the fermentation medium for better productivity. In these treatments, the highest figures of bioethanol productivity, bioethanol yield and conversion coefficient were obtained. Using SBP as sole carbon source on YFM medium gave a negative effect on the growth and bioethanol production by both strains to record the lowest figures being 1.0 and 2.01 $\mathrm{gl}^{-1}$ for Sacch. cerevisiae B1 and 1.08 and $5.5 \mathrm{gl}^{-1}$ for Cl. Iusitaniae Gr45, respectively. Also, the lowest value of final $\mathrm{pH}$ was recorded in this treatment.

\section{Fruit juice waste (FJW)}

This experiment was initiated to determine the optimal bioethanol production conditions for high efficiency bioethanol production from the fruit juice waste (FJW) at different concentrations. Results in Tables 12 and 13 proved the significant effect of all FJW concentrations on bioethanol production by Sacch. cerevisiae B1 whereas no significant effect could be detected either between 100 and $120 \mathrm{mll}^{-1}$ or between 130 and150 $\mathrm{ml} \mathrm{I}^{-1}$ concentrations on bioethanol production by $\mathrm{Cl}$. lusitaniae $\mathrm{Gr} 45$. The highest bioethanol production by $\mathrm{Cl}$. Iusitaniae Gr45 and Sacch. cerevisiae B1 were attained on FJW at 130 and $150 \mathrm{mll}^{-1}$ concentrations being 17.2 and $19.9 \mathrm{gl}^{-1}$, respectively. These treatments attained productivity and bioethanol yield, being 0.28 $\mathrm{gl}^{-1} \mathrm{~h}^{-1}$ and $37.4 \%$ for Sacch. cerevisiae B1 and $0.24 \mathrm{gl}^{-1} \mathrm{~h}^{-1}$ and $32.33 \%$ for $\mathrm{Cl}$. Iusitaniae Gr45, respectively.

In this respect, Lin and Tanaka (2006) stated that substrates like fruits wastes, sugar cane, sugar beets, sweet sorghum and molasses already have sugars and once simple sugars are present, enzymes from microorganisms can readily ferment them to bioethanol. Starches must firstly be hydrolyzed to fermentable sugars by the action of enzymes and cellulose must likewise be converted into sugars, generally by the action of mineral acids. Also, Dhillon et al. (2013) mentioned that apple-processing industries generate huge quantities of wastes 'apple pomace' (skin, pulp and seeds) and juice. It can be used as a promising raw material for direct extraction of bioactive compounds and bio production of high value-added products, such as enzymes, organic acids and biofuels. 
Table 1. Total sugars and nitrogen content of agro-industrial byproducts.

\begin{tabular}{|l|c|c|}
\hline \multicolumn{1}{|c|}{ Agro-industrial byproducts } & Total sugars (\%) & Total Nitrogen (\%) \\
\hline Sawdust & 36.8 & 0.24 \\
\hline Sugar cane Bagasse & 45.2 & 0.45 \\
\hline Corncobs waste & 45.6 & 0.53 \\
\hline Sugar beet pulp & 44.5 & 1.84 \\
\hline Fruit Juice waste & 35.4 & 2.50 \\
\hline Black strap cane molasses & 48.3 & 0.80 \\
\hline
\end{tabular}

Table 2. Effect of different sugar cane molasses treatments at different concentrations on bioethanol production by $\mathrm{Cl}$. Iusitaniae Gr45 after 3 days incubation at $30^{\circ} \mathrm{C}$ as a static batch culture.*

\begin{tabular}{|c|c|c|c|}
\hline Treatments & $\begin{array}{c}\text { Bioethanol } \\
\text { concentration } \\
\left(\mathrm{gl}^{-1}\right)\end{array}$ & $\begin{array}{l}\text { Bioethanol } \\
\text { productivity } \\
\left(\mathrm{gl}^{-1} \mathrm{~h}^{-1}\right)\end{array}$ & $\begin{array}{c}\text { Final } \\
\mathrm{pH}\end{array}$ \\
\hline YFM complete medium (control) & $12.45 \mathrm{a}$ & 0.17 & 3.5 \\
\hline YFM - glucose $+2 \%$ sugar cane molasses & $4.62 \mathrm{k}$ & 0.06 & 4.8 \\
\hline YFM - glucose $+4 \%$ sugar cane molasses & $5.11 \mathrm{i}$ & 0.07 & 4.9 \\
\hline YFM - glucose $+6 \%$ sugar cane molasses & $7.00 \mathrm{e}$ & 0.09 & 4.6 \\
\hline YFM - glucose $+8 \%$ sugar cane molasses & $8.12 \mathrm{~d}$ & 0.11 & 4.7 \\
\hline YFM - glucose $+10 \%$ sugar cane molasses & $9.80 \mathrm{~b}$ & 0.13 & 4.5 \\
\hline Yeast extract $+2 \%$ sugar cane molasses & $4.55 \mathrm{~L}$ & 0.06 & 5.7 \\
\hline Yeast extract $+4 \%$ sugar cane molasses & $4.69 \mathrm{~J}$ & 0.06 & 5.0 \\
\hline Yeast extract+ $6 \%$ sugar cane molasses & $4.69 \mathrm{~J}$ & 0.06 & 4.8 \\
\hline Yeast extract $+8 \%$ sugar cane molasses & $6.79 \mathrm{~F}$ & 0.09 & 4.7 \\
\hline Yeast extract+ $10 \%$ sugar cane molasses & $8.33 \mathrm{c}$ & 0.11 & 4.7 \\
\hline$\left(\mathrm{NH}_{4}\right)_{2} \mathrm{SO}_{4}+2 \%$ sugar cane molasses & 2.310 & 0.03 & 5.0 \\
\hline$\left(\mathrm{NH}_{4}\right)_{2} \mathrm{SO}_{4}+4 \%$ sugar cane molasses & $5.74 \mathrm{~h}$ & 0.07 & 5.0 \\
\hline$\left(\mathrm{NH}_{4}\right)_{2} \mathrm{SO}_{4}+6 \%$ sugar cane molasses & $6.68 \mathrm{~J}$ & 0.09 & 4.7 \\
\hline$\left(\mathrm{NH}_{4}\right)_{2} \mathrm{SO}_{4}+8 \%$ sugar cane molasses & $7.00 \mathrm{e}$ & 0.09 & 4.7 \\
\hline$\left(\mathrm{NH}_{4}\right)_{2} \mathrm{SO}_{4}+10 \%$ sugar cane molasses & $8.12 \mathrm{~d}$ & 0.11 & 4.7 \\
\hline $2 \%$ sugar cane molasses & $3.78 n$ & 0.05 & 5.1 \\
\hline $4 \%$ sugar cane molasses & $4.34 \mathrm{~m}$ & 0.06 & 4.8 \\
\hline $6 \%$ sugar cane molasses & $4.34 \mathrm{~m}$ & 0.06 & 4.8 \\
\hline $8 \%$ sugar cane molasses & $5.88 \mathrm{~g}$ & 0.08 & 4.7 \\
\hline $10 \%$ sugar cane molasses & $7.00 \mathrm{e}$ & 0.09 & 4.6 \\
\hline
\end{tabular}

* The values are mean of three replicates.

Productivity = Bioethanol concentration $\left(\mathrm{gl}^{-1}\right) /$ fermentation time $(\mathrm{h})=\mathrm{gl}^{-1} \mathrm{~h}^{-1}$ (Gamal et al., 1991).

Values in the same parameter followed by the same latter do not significantly differ from each other, according to Duncan's at $5 \%$ level. 
Table 3. Effect of different sugar cane molasses treatments at different concentrations on bioethanol production by Sacch. cerevisiae B1 after 3 days incubation at $30^{\circ} \mathrm{C}$ as a static batch culture. *

\begin{tabular}{|c|c|c|c|}
\hline Treatments & $\begin{array}{c}\text { Bioethanol } \\
\text { concentration } \\
\left(\mathrm{gl}^{-1}\right)\end{array}$ & $\begin{array}{c}\text { Bioethanol } \\
\text { productivity } \\
\left(\mathrm{gl}^{-1} \mathrm{~h}^{-1}\right)\end{array}$ & $\begin{array}{c}\text { Final } \\
\mathrm{pH}\end{array}$ \\
\hline YFM complete medium (control) & $11.80 \mathrm{~d}$ & 0.16 & 3.2 \\
\hline YFM - glucose $+2 \%$ sugar cane molasses & $8.70 \mathrm{~g}$ & 0.12 & 4.6 \\
\hline YFM - glucose $+4 \%$ sugar cane molasses & $13.05 \mathrm{a}$ & 0.18 & 4.6 \\
\hline YFM - glucose $+6 \%$ sugar cane molasses & $12.43 \mathrm{~b}$ & 0.17 & 4.6 \\
\hline YFM - glucose $+8 \%$ sugar cane molasses & $11.75 \mathrm{~d}$ & 0.16 & 4.6 \\
\hline YFM - glucose $+10 \%$ sugar cane molasses & $11.75 \mathrm{~d}$ & 0.16 & 4.6 \\
\hline Yeast extract $+2 \%$ sugar cane molasses & $9.60 f$ & 0.13 & 4.8 \\
\hline Yeast extract+ $4 \%$ sugar cane molasses & $9.60 f$ & 0.13 & 4.6 \\
\hline Yeast extract+ $6 \%$ sugar cane molasses & $13.05 \mathrm{a}$ & 0.18 & 4.6 \\
\hline Yeast extract+ $8 \%$ sugar cane molasses & $12.43 \mathrm{~b}$ & 0.17 & 4.6 \\
\hline Yeast extract $+10 \%$ sugar cane molasses & $12.20 \mathrm{c}$ & 0.16 & 4.6 \\
\hline$\left(\mathrm{NH}_{4}\right)_{2} \mathrm{SO}_{4}+2 \%$ sugar cane molasses & 10.17 e & 0.14 & 4.6 \\
\hline$\left(\mathrm{NH}_{4}\right)_{2} \mathrm{SO}_{4}+4 \%$ sugar cane molasses & 10.17 e & 0.14 & 4.6 \\
\hline$\left(\mathrm{NH}_{4}\right)_{2} \mathrm{SO}_{4}+6 \%$ sugar cane molasses & $11.75 \mathrm{~d}$ & 0.16 & 4.5 \\
\hline$\left(\mathrm{NH}_{4}\right)_{2} \mathrm{SO}_{4}+8 \%$ sugar cane molasses & $12.20 \mathrm{c}$ & 0.17 & 4.5 \\
\hline$\left(\mathrm{NH}_{4}\right)_{2} \mathrm{SO}_{4}+10 \%$ sugar cane molasses & $12.43 \mathrm{~b}$ & 0.17 & 4.5 \\
\hline $2 \%$ sugar cane molasses & $9.60 \mathrm{f}$ & 0.13 & 4.7 \\
\hline $4 \%$ sugar cane molasses & $11.75 \mathrm{~d}$ & 0.16 & 4.6 \\
\hline $6 \%$ sugar cane molasses & $12.20 \mathrm{c}$ & 0.16 & 4.7 \\
\hline $8 \%$ sugar cane molasses & $12.43 \mathrm{~b}$ & 0.17 & 4.4 \\
\hline $10 \%$ sugar cane molasses & 13.05a & 0.18 & 4.6 \\
\hline
\end{tabular}

*The values are mean of three replicates.

Productivity = Bioethanol concentration $\left(\mathrm{gl}^{-1}\right) /$ fermentation time $(\mathrm{h})=\mathrm{gl}^{-1} \mathrm{~h}^{-1}($ Gamal et al., 1991).

Values in the same parameter followed by the same latter do not significantly differ from each other, according to Duncan's at $5 \%$ level. 
Table 4. Effect of different treatments of acid CW hydrolyzate on bioethanol production by $\mathrm{Cl}$. Iusitaniae $\mathrm{Gr} 45$ after 3 days incubation at $30^{\circ} \mathrm{C}$ as a static batch culture.*

\begin{tabular}{|c|c|c|c|c|c|c|c|c|}
\hline Treatments & $\begin{array}{c}\text { Growth } \\
(\mathrm{O} . \mathrm{D})\end{array}$ & $\begin{array}{c}\text { Residual } \\
\text { glucose } \\
\left(\mathrm{gl}^{-1}\right)\end{array}$ & $\begin{array}{c}\text { Consumed } \\
\text { glucose } \\
\left(\mathrm{gl}^{-1}\right)\end{array}$ & $\begin{array}{c}\text { Bioethanol } \\
\text { concentration } \\
\left(\mathrm{gl}^{-1}\right)\end{array}$ & $\begin{array}{c}\text { Bioethanol } \\
\text { productivity } \\
\left(\mathrm{gl}^{-1} \mathrm{~h}^{-1}\right)\end{array}$ & $\begin{array}{c}\text { Bioethanol } \\
\text { yield } \\
(\%)\end{array}$ & $\begin{array}{c}\text { Conversion } \\
\text { coefficient } \\
(\%)\end{array}$ & $\begin{array}{c}\text { Final } \\
\mathrm{pH}\end{array}$ \\
\hline $\begin{array}{c}\text { YFM complete } \\
\text { medium (control) }\end{array}$ & $2.50 \mathrm{a}$ & 0.055 & 50.00 & $12.45 \mathrm{~b}$ & 0.17 & 24.90 & 24.90 & 3.80 \\
\hline $\begin{array}{c}\text { YFM - glucose + } \\
\mathrm{CW} \text { hydrolyzate }\end{array}$ & $1.45 \mathrm{c}$ & 0.028 & 49.97 & $13.32 \mathrm{a}$ & 0.18 & 26.64 & 26.65 & 5.67 \\
\hline $\begin{array}{c}\text { YE }+\mathrm{CW} \\
\text { hydrolyzate }\end{array}$ & $1.52 \mathrm{~b}$ & 0.041 & 49.96 & $5.76 \mathrm{c}$ & 0.08 & 11.52 & 11.52 & 6.27 \\
\hline $\begin{array}{c}(\mathrm{NH})_{2} \mathrm{SO}_{4}+\mathrm{CW} \\
\text { hydrolyzate }\end{array}$ & $1.55 \mathrm{~b}$ & 0.006 & 49.99 & $3.24 \mathrm{~d}$ & 0.04 & 6.48 & 6.48 & 6.47 \\
\hline $\mathrm{CW}$ hydrolyzate & $1.46 \mathrm{c}$ & 0.018 & 49.98 & $0.72 \mathrm{e}$ & 0.01 & 1.44 & 1.44 & 6.14 \\
\hline
\end{tabular}

*The values are mean of three replicates.

Productivity = Bioethanol concentration $\left(\mathrm{gl}^{-1}\right) /$ fermentation time $(\mathrm{h})=\mathrm{gl}^{-1} \mathrm{~h}^{-1}($ Gamal et al., 1991).

Ethanol yield $(\%)=\left[\right.$ Bioethanol concentration $\left(\mathrm{gl}^{-1}\right) /$ initial sugars $\left.\left(\mathrm{gl}^{-1}\right)\right]$ bioethanol $\times 100$ (Gamal et al., 1991).

Conversion coefficient $(\%)=\left[\right.$ Bioethanol concentration $\left(\mathrm{gl}^{-1}\right) /$ consumed sugars $\left.\left(\mathrm{gl}^{-1}\right)\right] \times 100$ (Gamal et al., 1991).

Values in the same parameter followed by the same latter do not significantly differ from each other, according to Duncan's at $5 \%$ level.

Table 5. Effect of different treatments of acid CW hydrolyzate on ethanol production by Sacch. cerevisiae B1 after 3 days incubation at $30^{\circ} \mathrm{C}$ as a static batch culture.*

\begin{tabular}{|c|c|c|c|c|c|c|c|c|}
\hline Treatments & $\begin{array}{l}\text { Growth } \\
\text { (O.D) }\end{array}$ & $\begin{array}{c}\text { Residual } \\
\text { glucose } \\
\left(\mathrm{gl}^{-1}\right)\end{array}$ & $\begin{array}{l}\text { Consume } \\
\mathrm{d} \text { glucose } \\
\left(\mathrm{g}^{-1}\right)\end{array}$ & $\begin{array}{c}\text { Bioethanol } \\
\text { concentration } \\
\left(\mathrm{gl}^{-1}\right)\end{array}$ & $\begin{array}{c}\text { Bioethanol } \\
\text { productivity } \\
\left(\mathrm{gl}^{-1} \mathrm{~h}^{-1}\right)\end{array}$ & $\begin{array}{l}\text { Bioeth } \\
\text { anol } \\
\text { yield } \\
(\%)\end{array}$ & $\begin{array}{c}\text { Conversion } \\
\text { coefficient } \\
(\%)\end{array}$ & $\begin{array}{c}\text { Final } \\
\mathrm{pH}\end{array}$ \\
\hline $\begin{array}{l}\text { YFM complete } \\
\text { medium (control) }\end{array}$ & $1.9 \mathrm{a}$ & 0.247 & 49.75 & $11.50 \mathrm{a}$ & 0.16 & $\begin{array}{c}23.0 \\
0\end{array}$ & 23.00 & 3.0 \\
\hline $\begin{array}{l}\text { YFM - glucose + } \\
\text { CW hydrolyzate }\end{array}$ & $1.8 \mathrm{~b}$ & 0.413 & 49.58 & $2.03 \mathrm{c}$ & 0.03 & 4.06 & 4.09 & 4.6 \\
\hline $\begin{array}{l}\text { YE + CW } \\
\text { hydrolyzate }\end{array}$ & $1.3 \mathrm{c}$ & 0.540 & 49.46 & $2.53 \mathrm{~b}$ & 0.04 & 5.06 & 5.11 & 4.9 \\
\hline $\begin{array}{c}\left(\mathrm{NH}_{4}\right)_{2} \mathrm{SO}_{4}+\mathrm{CW} \\
\text { hydrolyzate }\end{array}$ & $1.1 \mathrm{~d}$ & 0.114 & 49.85 & $2.01 \mathrm{c}$ & 0.03 & 4.02 & 4.02 & 4.9 \\
\hline CW hydrolyzate & $1.1 \mathrm{~d}$ & 0.091 & 49.90 & $1.50 \mathrm{~d}$ & 0.02 & 3.00 & 3.00 & 4.9 \\
\hline
\end{tabular}

*The values are mean of three replicates.

Productivity = Bioethanol concentration $\left(\mathrm{gl}^{-1}\right) /$ fermentation time $(\mathrm{h})=\mathrm{gl}^{-1} \mathrm{~h}^{-1}$ (Gamal et al., 1991).

Bioethanol yield $(\%)=\left[\right.$ Bioethanol concentration $\left(\mathrm{gl}^{-1}\right) /$ initial sugars $\left.\left(\mathrm{gl}^{-1}\right)\right]$ x100 (Gamal et al., 1991).

Conversion coefficient $(\%)=\left[\right.$ Bioethanol concentration $\left(\mathrm{gl}^{-1}\right) /$ consumed sugars $\left.\left(\mathrm{gl}^{-1}\right)\right] \times 100$ (Gamal et al., 1991).

Values in the same parameter followed by the same latter do not significantly differ from each other, according to Duncan's at $5 \%$ level. 
Table 6. Effect of different treatments of acid sugar cane bagasse (SB) hydrolyzate on bioethanol production by $\mathrm{Cl}$. lusitaniae $\mathrm{Gr} 45$ after 3 days incubation at $30^{\circ} \mathrm{C}$ as a static batch culture.*

\begin{tabular}{|c|c|c|c|c|c|c|c|c|}
\hline Treatments & $\begin{array}{c}\text { Growth } \\
\text { (O.D) }\end{array}$ & $\begin{array}{c}\text { Residual } \\
\text { glucose } \\
\left(\mathrm{gl}^{-1}\right)\end{array}$ & $\begin{array}{c}\text { Consume } \\
\mathrm{d} \text { glucose } \\
\left(\mathrm{gl}^{-1}\right)\end{array}$ & $\begin{array}{c}\text { Bioethanol } \\
\text { concentration } \\
\left(\mathrm{gl}^{-1}\right)\end{array}$ & $\begin{array}{c}\text { Bioethanol } \\
\text { productivity } \\
\left(\mathrm{gl}^{-1} \mathrm{~h}^{-1}\right)\end{array}$ & $\begin{array}{c}\text { Bioethanol } \\
\text { yield } \\
(\%)\end{array}$ & $\begin{array}{c}\text { Conversion } \\
\text { coefficient } \\
(\%)\end{array}$ & $\begin{array}{c}\text { Final } \\
\mathrm{pH}\end{array}$ \\
\hline $\begin{array}{c}\text { YFM complete medium } \\
\text { (control) }\end{array}$ & $2.50 \mathrm{a}$ & 0.055 & 50.00 & $12.3 \mathrm{~b}$ & 0.17 & 24.6 & 24.6 & 3.8 \\
\hline $\begin{array}{c}\text { YFM - glucose + SB } \\
\text { hydrolyzate }\end{array}$ & $1.11 \mathrm{~d}$ & 0.034 & 43.97 & $15.8 \mathrm{a}$ & 0.22 & 31.6 & 35.9 & 5.4 \\
\hline $\begin{array}{c}\text { YE + SB hydrolyzate } \\
\text { (NH })_{2} \mathrm{SO}{ }_{4}+\text { SB hydrolyzate }\end{array}$ & $1.76 \mathrm{~b}$ & 0.024 & 49.98 & $9.7 \mathrm{~b}$ & 0.13 & 19.4 & 19.4 & 6.4 \\
\hline SB hydrolyzate & $1.22 \mathrm{c}$ & 0.021 & 49.98 & $6.5 \mathrm{~d}$ & 0.09 & 13.0 & 13.6 & 13.6 \\
\hline
\end{tabular}

*The values are mean of three replicates

Productivity = Bioethanol concentration $\left(\mathrm{gl}^{-1}\right) /$ fermentation time $(\mathrm{h})=\mathrm{gl}^{-1} \mathrm{~h}^{-1}$ (Gamal et al., 1991).

Bioethanol yield $(\%)=\left[\right.$ Bioethanol concentration $\left(\mathrm{gl}^{-1}\right) /$ initial sugars $\left.\left(\mathrm{gl}^{-1}\right)\right] \times 100$ (Gamal et al., 1991).

Conversion coefficient $(\%)=\left[\right.$ Bioethanol concentration $\left(\mathrm{gl}^{-1}\right) /$ consumed sugars $\left.\left(\mathrm{gl}^{-1}\right)\right] \times 100$ (Gamal et al., 1991).

Values in the same parameter followed by the same latter do not significantly differ from each other, according to Duncan's at $5 \%$ level.

Table 7. Effect of different treatments of acid sugar cane bagasse (SB) hydrolyzate on bioethanol production by Sacch. cerevisiae B1 after 3 days incubation at $30^{\circ} \mathrm{C}$ as a static batch culture.*

\begin{tabular}{|c|c|c|c|c|c|c|c|c|}
\hline Treatments & $\begin{array}{c}\text { Growth } \\
\text { (O.D) }\end{array}$ & $\begin{array}{l}\text { Residual } \\
\text { glucose } \\
\left(\mathrm{gl}^{-1}\right)\end{array}$ & $\begin{array}{l}\text { Consumed } \\
\text { glucose } \\
\left(\mathrm{gl}^{-1}\right)\end{array}$ & $\begin{array}{c}\text { Bioethanol } \\
\text { concentration } \\
\left(\mathrm{gl}^{-1}\right)\end{array}$ & $\begin{array}{c}\text { Bioethanol } \\
\text { productivity } \\
\left(\mathrm{gl}^{-1} \mathrm{~h}^{-1}\right)\end{array}$ & $\begin{array}{c}\text { Bioethanol } \\
\text { yield } \\
(\%)\end{array}$ & $\begin{array}{c}\text { Conversion } \\
\text { coefficient } \\
(\%)\end{array}$ & $\begin{array}{c}\text { Final } \\
\mathrm{pH}\end{array}$ \\
\hline $\begin{array}{l}\text { YFM complete medium } \\
\text { (control) }\end{array}$ & $1.9 \mathrm{a}$ & 0.247 & 49.75 & $11.52 \mathrm{a}$ & 0.16 & 23.04 & 23.10 & 3.0 \\
\hline $\begin{array}{c}\text { YFM - glucose + SB } \\
\text { hydrolyzate }\end{array}$ & $1.8 \mathrm{~b}$ & 0.540 & 49.46 & $4.50 \mathrm{~b}$ & 0.06 & 9.00 & 9.03 & 4.9 \\
\hline YE + SB hydrolyzate & $1.7 \mathrm{c}$ & 0.450 & 49.55 & $4.03 c$ & 0.05 & 0.05 & 8.13 & 5.1 \\
\hline$\left(\mathrm{NH}_{4}\right)_{2} \mathrm{SO}_{4}+\mathrm{SB}$ hydrolyzate & $1.4 \mathrm{~d}$ & 0.440 & 49.56 & $3.51 \mathrm{~d}$ & 0.05 & 0.05 & 7.08 & 4.9 \\
\hline SB hydrolyzate & $1.4 \mathrm{~d}$ & 0.200 & 49.80 & $2.97 \mathrm{e}$ & 0.04 & 6.00 & 6.00 & 5.1 \\
\hline
\end{tabular}

*The values are mean of three replicates.

Productivity = Bioethanol concentration $\left(\mathrm{gl}^{-1}\right) /$ fermentation time $(\mathrm{h})=\mathrm{gl}^{-1} \mathrm{~h}^{-1}$ (Gamal et al., 1991).

Bioethanol yield $(\%)=\left[\right.$ Bioethanol concentration $\left(\mathrm{gl}^{-1}\right) /$ initial sugars $\left.\left(\mathrm{gl}^{-1}\right)\right] \times 100$ (Gamal et al., 1991).

Conversion coefficient $(\%)=\left[\right.$ Bioethanol concentration $\left(\mathrm{gl}^{-1}\right) /$ consumed sugars $\left.\left(\mathrm{gl}^{-1}\right)\right] \times 100$ (Gamal et al., 1991).

Values in the same parameter followed by the same latter do not significantly differ from each other, according to Duncan's at $5 \%$ level. 
Table 8. Effect of different treatments of acid sawdust (SD) hydrolyzate on bioethanol production by $\mathrm{Cl}$. Iusitaniae $\mathrm{Gr} 45$ after 3 days incubation at $30^{\circ} \mathrm{C}$ as a static batch culture.*

\begin{tabular}{|c|c|c|c|c|c|c|c|c|}
\hline Treatments & $\begin{array}{l}\text { Growth } \\
\text { (O.D) }\end{array}$ & $\begin{array}{l}\text { Residual } \\
\text { glucose } \\
\left(\mathrm{gl}^{-1}\right)\end{array}$ & $\begin{array}{l}\text { Consumed } \\
\text { glucose } \\
\left(\mathrm{gl}^{-1}\right)\end{array}$ & $\begin{array}{c}\text { Bioethanol } \\
\text { concentration } \\
\qquad\left(\mathrm{gl}^{-1}\right)\end{array}$ & $\begin{array}{l}\text { Bioethanol } \\
\text { productivity } \\
\left(\mathrm{gl}^{-1} \mathrm{~h}^{-1}\right)\end{array}$ & $\begin{array}{c}\text { Bioethanol } \\
\text { yield } \\
(\%)\end{array}$ & $\begin{array}{c}\text { Conversion } \\
\text { coefficient } \\
(\%)\end{array}$ & $\begin{array}{c}\text { Final } \\
\mathrm{pH}\end{array}$ \\
\hline $\begin{array}{l}\text { YFM complete } \\
\text { medium (control) }\end{array}$ & $2.50 \mathrm{a}$ & 0.06 & 50.00 & $12.52 \mathrm{e}$ & 0.17 & 25.04 & 25.04 & 3.80 \\
\hline $\begin{array}{l}\text { YFM - glucose + } \\
\text { SD hydrolyzate }\end{array}$ & $1.21 \mathrm{c}$ & 0.06 & 43.94 & $12.60 \mathrm{~d}$ & 0.18 & 25.20 & 28.68 & 5.52 \\
\hline $\begin{array}{c}\text { YE + SD } \\
\text { hydrolyzate }\end{array}$ & $1.65 b$ & 0.03 & 49.98 & $16.50 \mathrm{a}$ & 0.23 & 33.00 & 33.00 & 6.65 \\
\hline $\begin{array}{c}\left(\mathrm{NH}_{4}\right)_{2} \mathrm{SO}_{4}+\mathrm{SD} \\
\text { hydrolyzate }\end{array}$ & $1.15 \mathrm{c}$ & 0.09 & 49.91 & $13.54 \mathrm{c}$ & 0.19 & 27.10 & 27.13 & 6.27 \\
\hline SD hydrolyzate & $1.07 d$ & 0.00 & 50.00 & $13.76 \mathrm{~b}$ & 0.19 & 27.50 & 27.50 & 6.43 \\
\hline
\end{tabular}

*The values are mean of three replicates.

Productivity = Bioethanol concentration $\left(\mathrm{gl}^{-1}\right) /$ fermentation time $(\mathrm{h})=\mathrm{gl}^{-1} \mathrm{~h}^{-1}$ (Gamal et al., 1991).

Bioethanol yield $(\%)=\left[\right.$ Bioethanol concentration $\left(\mathrm{gl}^{-1}\right) /$ initial sugars $\left.\left(\mathrm{gl}^{-1}\right)\right] \times 100$ (Gamal et al., 1991).

Conversion coefficient $(\%)=\left[\right.$ Bioethanol concentration $\left(\mathrm{gl}^{-1}\right) /$ consumed sugars $\left.\left(\mathrm{gl}^{-1}\right)\right] \times 100$ (Gamal et al., 1991).

Values in the same parameter followed by the same latter do not significantly differ from each other, according to Duncan's at $5 \%$ level.

Table 9. Effect of different treatments of acid sawdust (SD) hydrolyzate on bioethanol production by Sacch. cerevisiae B1 after 3 days incubation at $30^{\circ} \mathrm{C}$ as a static batch culture. *

\begin{tabular}{|c|c|c|c|c|c|c|c|c|}
\hline Treatments of YFM medium & $\begin{array}{l}\text { Growth } \\
(O . D)\end{array}$ & $\begin{array}{l}\text { Residual } \\
\text { glucose } \\
\left(\mathrm{gl}^{-1}\right)\end{array}$ & $\begin{array}{l}\text { Consumed } \\
\text { glucose } \\
\left(\mathrm{gl}^{-1}\right)\end{array}$ & $\begin{array}{c}\text { Bioethanol } \\
\text { concentration } \\
\left(\mathrm{gl}^{-1}\right)\end{array}$ & $\begin{array}{l}\text { Bioethanol } \\
\text { productivity } \\
\left(\mathrm{gl}^{-1} \mathrm{~h}^{-1}\right)\end{array}$ & $\begin{array}{c}\text { Bioethanol } \\
\text { yield } \\
(\%)\end{array}$ & $\begin{array}{c}\text { Conversion } \\
\text { coefficient } \\
(\%)\end{array}$ & $\begin{array}{c}\text { Final } \\
\mathrm{pH}\end{array}$ \\
\hline $\begin{array}{l}\text { YFM complete medium } \\
\text { (control) }\end{array}$ & $1.9 \mathrm{a}$ & 0.247 & 49.75 & $11.50 \mathrm{a}$ & 0.16 & 23.00 & 23.11 & 3.0 \\
\hline $\begin{array}{c}\text { YFM - glucose + SD } \\
\text { hydrolyzate }\end{array}$ & $1.1 \mathrm{~b}$ & 0.200 & 49.80 & $4.97 b$ & 0.05 & 9.94 & 9.98 & 4.8 \\
\hline YE + SD hydrolyzate & $0.9 \mathrm{c}$ & 0.280 & 49.72 & $2.53 c$ & 0.04 & 5.06 & 5.08 & 4.9 \\
\hline $\begin{array}{c}\left(\mathrm{NH}_{4}\right)_{2} \mathrm{SO}_{4}+\mathrm{SD} \\
\text { hydrolyzate }\end{array}$ & $0.9 \mathrm{c}$ & 0.097 & 49.90 & $2.01 \mathrm{~d}$ & 0.03 & 4.02 & 4.02 & 4.9 \\
\hline SD hydrolyzate & $0.8 \mathrm{~d}$ & 0.091 & 49.90 & $1.49 \mathrm{e}$ & 0.02 & 2.98 & 2.98 & 4.9 \\
\hline
\end{tabular}

*The values are mean of three replicates.

Productivity = Bioethanol concentration $\left(\mathrm{gl}^{-1}\right) /$ fermentation time $(\mathrm{h})=\mathrm{gl}^{-1} \mathrm{~h}^{-1}$ (Gamal et al., 1991).

Bioethanol yield $(\%)=\left[\right.$ Bioethanol concentration $\left(\mathrm{gl}^{-1}\right) /$ initial sugars $\left.\left(\mathrm{gl}^{-1}\right)\right] \times 100$ (Gamal et al., 1991).

Conversion coefficient $(\%)=\left[\right.$ Bioethanol concentration $\left(\mathrm{gl}^{-1}\right) /$ consumed sugars $\left.\left(\mathrm{gl}^{-1}\right)\right] \times 100$ (Gamal et al., 1991).

Values in the same parameter followed by the same latter do not significantly differ from each other, according to Duncan's at $5 \%$ level. 
Table 10. Effect of different treatments of sugar beet pulp (SBP) hydrolyzate on bioethanol production by $\mathrm{Cl}$. Iusitaniae $\mathrm{Gr} 45$ after 3 days incubation at $30^{\circ} \mathrm{C}$ as astatic batch culture.*

\begin{tabular}{|c|c|c|c|c|c|c|c|c|}
\hline Treatments & $\begin{array}{c}\text { Growth } \\
(\mathrm{O} . \mathrm{D})\end{array}$ & $\begin{array}{c}\text { Residual } \\
\text { glucose } \\
\left(\mathrm{gl}^{-1}\right)\end{array}$ & $\begin{array}{c}\text { Consumed } \\
\text { glucose } \\
\left(\mathrm{gl}^{-1}\right)\end{array}$ & $\begin{array}{c}\text { Bioethanol } \\
\text { concentration } \\
\left(\mathrm{gl}^{-1}\right)\end{array}$ & $\begin{array}{c}\text { Bioethanol } \\
\text { productivity } \\
\left(\mathrm{gl}^{-1} \mathrm{~h}^{-1}\right)\end{array}$ & $\begin{array}{c}\text { Bioethanol } \\
\text { yield } \\
(\%)\end{array}$ & $\begin{array}{c}\text { Conversion } \\
\text { coefficient } \\
(\%)\end{array}$ & $\begin{array}{c}\text { Final } \\
\mathrm{pH}\end{array}$ \\
\hline $\begin{array}{c}\text { YFM complete } \\
\text { medium } \\
\text { (control) }\end{array}$ & $2.50 \mathrm{a}$ & 0.055 & 49.995 & $12.50 \mathrm{a}$ & 0.17 & 25.00 & 25.00 & 3.80 \\
\hline $\begin{array}{c}\mathrm{YFM}-\text { glucose } \\
+\mathrm{SBP} \text { extract }\end{array}$ & $1.08 \mathrm{~d}$ & 0.064 & 49.936 & $5.50 \mathrm{e}$ & 0.08 & 11.00 & 11.00 & 5.72 \\
\hline $\begin{array}{c}\mathrm{YE}+\mathrm{SBP} \\
\text { extract }\end{array}$ & $1.92 \mathrm{~b}$ & 0.005 & 49.995 & $8.51 \mathrm{c}$ & 0.12 & 17.02 & 17.02 & 6.77 \\
\hline $\begin{array}{c}(\mathrm{NH})_{4} \mathrm{SO}_{4}+ \\
\mathrm{SBP} \text { extract }\end{array}$ & $1.70 \mathrm{C}$ & 0.158 & 49.842 & $10.73 \mathrm{~b}$ & 0.15 & 21.46 & 21.50 & 6.80 \\
\hline $\mathrm{SBP}^{\mathrm{S}}$ extract & $1.73 \mathrm{C}$ & 0.248 & 49.752 & $7.40 \mathrm{~d}$ & 0.10 & 14.80 & 14.80 & 6.84 \\
\hline
\end{tabular}

*The values are mean of three replicates.

Productivity = Bioethanol concentration $\left(\mathrm{gl}^{-1}\right) /$ fermentation time $(\mathrm{h})=\mathrm{gl}^{-1} \mathrm{~h}^{-1}$ (Gamal et al., 1991).

Bioethanol yield $(\%)=\left[\right.$ Bioethanol concentration $\left(\mathrm{gl}^{-1}\right) /$ initial sugars $\left.\left(\mathrm{gl}^{-1}\right)\right] \times 100$ (Gamal et al., 1991).

Conversion coefficient $(\%)=\left[\right.$ Bioethanol concentration $\left(\mathrm{gl}^{-1}\right) /$ consumed sugars $\left.\left(\mathrm{gl}^{-1}\right)\right]$ x100 (Gamal et al., 1991).

Values in the same parameter followed by the same latter do not significantly differ from each other, according to Duncan's at $5 \%$ level.

Table 11. Effect of different treatments of sugar beet pulp (SBP) hydrolyzate on bioethanol production by Sacch. cerevisiae B1 after 3 days incubation at $30^{\circ} \mathrm{C}$ as a static batch culture.*

\begin{tabular}{|c|c|c|c|c|c|c|c|c|}
\hline Treatments & $\begin{array}{l}\text { Growth } \\
\text { (O.D) }\end{array}$ & $\begin{array}{c}\text { Residual } \\
\text { glucose } \\
\left(\mathrm{gl}^{-1}\right)\end{array}$ & $\begin{array}{l}\text { Consumed } \\
\text { glucose } \\
\left(\mathrm{gl}^{-1}\right)\end{array}$ & $\begin{array}{c}\text { Bioethanol } \\
\text { concentration } \\
\left(\mathrm{gl}^{-1}\right)\end{array}$ & $\begin{array}{c}\text { Bioethanol } \\
\text { productivity } \\
\left(\mathrm{gl}^{-1} \mathrm{~h}^{-1}\right)\end{array}$ & $\begin{array}{c}\text { Bioethanol } \\
\text { yield } \\
(\%)\end{array}$ & $\begin{array}{c}\text { Conversion } \\
\text { coefficient } \\
(\%)\end{array}$ & $\begin{array}{c}\text { Final } \\
\mathrm{pH}\end{array}$ \\
\hline $\begin{array}{c}\text { YFM complete } \\
\text { medium (control) }\end{array}$ & $1.9 \mathrm{a}$ & 0.247 & 49.75 & $11.40 \mathrm{a}$ & 0.16 & 22.80 & 22.90 & 3.0 \\
\hline $\begin{array}{c}\text { YFM - glucose + } \\
\text { SBP extract }\end{array}$ & $1.0 \mathrm{~b}$ & 0.449 & 49.56 & $2.01 \mathrm{~d}$ & 0.03 & 4.02 & 4.05 & 5.1 \\
\hline $\mathrm{YE}+\mathrm{SBP}$ extract & $0.8 \mathrm{~d}$ & 0.131 & 49.89 & $4.03 \mathrm{~b}$ & 0.06 & 8.06 & 8.07 & 5.2 \\
\hline $\begin{array}{c}\left(\mathrm{NH}_{4}\right)_{2} \mathrm{SO}_{4}+\mathrm{SBP} \\
\text { extract }\end{array}$ & $1.0 \mathrm{~b}$ & 0.102 & 49.89 & $2.53 \mathrm{c}$ & 0.04 & 5.06 & 5.07 & 5.2 \\
\hline SBP extract & $0.9 \mathrm{c}$ & 0.165 & 49.83 & $2.01 \mathrm{~d}$ & 0.03 & 4.02 & 4.03 & 5.2 \\
\hline
\end{tabular}

*The values are mean of three replicates.

Productivity = Bioethanol concentration $\left(\mathrm{gl}^{-1}\right) /$ fermentation time $(\mathrm{h})=\mathrm{gl}^{-1} \mathrm{~h}^{-1}$ (Gamal et al., 1991).

Bioethanol yield $(\%)=\left[\right.$ Bioethanol concentration $\left(\mathrm{gl}^{-1}\right) /$ initial sugars $\left.\left(\mathrm{gl}^{-1}\right)\right] \times 100$ (Gamal et al., 1991).

Conversion coefficient $(\%)=\left[\right.$ Bioethanol concentration $\left(\mathrm{gl}^{-1}\right) /$ consumed sugars $\left.\left(\mathrm{gl}^{-1}\right)\right]$ x100 (Gamal et al., 1991).

Values in the same parameter followed by the same latter do not significantly differ from each other, according to Duncan's

at $5 \%$ level. 
Table 12. Effect of different concentrations of fruit juice waste (FJW) on bioethanol production by $\mathrm{Cl}$. Iusitaniae $\mathrm{Gr} 45$ after 3 days incubation at $30^{\circ} \mathrm{C}$ as a static batch culture. *

\begin{tabular}{|c|c|c|c|c|c|}
\hline $\begin{array}{c}\text { FJW concentration } \\
\left(\mathrm{ml} \mathrm{l}^{-1}\right)\end{array}$ & $\begin{array}{c}\text { Initial total sugar } \\
\left(\mathrm{gl}^{-1}\right)\end{array}$ & $\begin{array}{c}\text { Bioethanol } \\
\text { concentration } \\
\left(\mathrm{gl}^{-1}\right)\end{array}$ & $\begin{array}{c}\text { Bioethanol } \\
\text { productivity } \\
\left(\mathrm{gl}^{-1} \mathrm{~h}^{-1}\right)\end{array}$ & $\begin{array}{c}\text { Bioethanol } \\
\text { yield } \\
(\%)\end{array}$ & $\begin{array}{c}\text { Final } \\
\mathrm{pH}\end{array}$ \\
\hline 80 & 28.3 & $3.50 \mathrm{c}$ & 0.049 & 12.37 & 4.33 \\
\hline 100 & 35.4 & $10.01 \mathrm{~b}$ & 0.140 & 28.28 & 4.23 \\
\hline 120 & 42.5 & $15.88 \mathrm{~b}$ & 0.220 & 37.36 & 4.37 \\
\hline 130 & 46.0 & $17.20 \mathrm{a}$ & 0.240 & 37.39 & 4.17 \\
\hline 150 & 53.1 & $17.20 \mathrm{a}$ & 0.240 & 32.39 & 4.45 \\
\hline
\end{tabular}

*The values are mean of three replicates.

Productivity = Bioethanol concentration $\left(\mathrm{gl}^{-1}\right) /$ fermentation time $(\mathrm{h})=\mathrm{gl}^{-1} \mathrm{~h}^{-1}$ (Gamal et al., 1991).

Bioethanol yield $(\%)=$ Bioethanol concentration ( $\mathrm{gl}-1) /$ initial sugars ( $\mathrm{gl}-1)$ x100 (Gamal et al., 1991).

Values in the same parameter followed by the same latter do not significantly differ from each other, according to Duncan's at $5 \%$ level.

Table 13. Effect of different concentrations of fruit juice waste (FJW) on bioethanol production by Sacch. cerevisiae B1 after 3 days incubation at $30^{\circ} \mathrm{C}$ as a static batch culture.*

\begin{tabular}{|c|c|c|c|c|c|}
\hline $\begin{array}{c}\text { FJW Concentration } \\
\left(\mathrm{ml} \mathrm{l}^{-1}\right)\end{array}$ & $\begin{array}{c}\text { Initial total } \\
\text { sugar }\left(\mathrm{g} \mathrm{I}^{-1}\right)\end{array}$ & $\begin{array}{c}\text { Bioethanol } \\
\text { concentration } \\
\left(\mathrm{gl}^{-1}\right)\end{array}$ & $\begin{array}{c}\text { Bioethanol } \\
\text { productivity } \\
\left(\mathrm{gl}^{-1} \mathrm{~h}^{-1}\right)\end{array}$ & $\begin{array}{c}\text { Bioethanol yield } \\
(\%)\end{array}$ & $\begin{array}{c}\text { Final } \\
\mathrm{pH}\end{array}$ \\
\hline 80 & 28.3 & $2.10 \mathrm{e}$ & 0.029 & 4.40 \\
\hline 100 & 35.4 & $12.06 \mathrm{~b}$ & 0.170 & 43.07 \\
\hline 120 & 42.5 & $17.96 \mathrm{a}$ & 0.250 & 4.14 \\
\hline 130 & 46.0 & $19.40 \mathrm{~d}$ & 0.270 & 42.26 \\
\hline 150 & 53.1 & $19.90 \mathrm{c}$ & 0.280 & 42.17 \\
\hline
\end{tabular}

*The values are mean of three replicates.

Productivity = Bioethanol concentration $\left(\mathrm{gl}^{-1}\right) /$ fermentation time $(\mathrm{h})=\mathrm{gl}^{-1} \mathrm{~h}^{-1}$ (Gamal et al., 1991).

Bioethanol yield $(\%)=$ Bioethanol concentration ( $\mathrm{gl}-1) /$ initial sugars (gl-1) x100 (Gamal et al., 1991).

Values in the same parameter followed by the same latter do not significantly differ from each other, according to Duncan's at $5 \%$ level. 
Table 14. Comparative data of maximum bioethanol production by Cl. Iusitaniae Gr 45 and Sacch. cerevisiae B1 on YFM medium and agroindustrial byproducts treatments.

\begin{tabular}{|c|c|c|c|c|c|c|c|c|}
\hline \multirow[b]{3}{*}{ Medium } & \multicolumn{8}{|c|}{ Bioethanol production } \\
\hline & \multicolumn{4}{|c|}{ Cl. Iusitaniae Gr 45} & \multicolumn{4}{|c|}{ Sacch. cerevisiae B1 } \\
\hline & $\begin{array}{l}\text { Conc. } \\
\left(\mathrm{gl}^{-1}\right)\end{array}$ & $\begin{array}{l}\text { Productivity } \\
\left(\mathrm{gl}^{-1} \mathrm{~h}^{-1}\right)\end{array}$ & $\begin{array}{l}\text { Yield } \\
(\%)\end{array}$ & $\begin{array}{c}\text { Conversion } \\
\text { coefficient } \\
(\%)\end{array}$ & $\begin{array}{l}\text { Conc. } \\
\left(\mathrm{gl}^{-1}\right)\end{array}$ & $\begin{array}{l}\text { Productivity } \\
\left(\mathrm{gl}^{-1} \mathrm{~h}^{-1}\right)\end{array}$ & $\begin{array}{l}\text { Yield } \\
(\%)\end{array}$ & $\begin{array}{c}\text { Conversion } \\
\text { coefficient } \\
(\%)\end{array}$ \\
\hline YFM & 12.45 & 0.17 & 25.00 & 25.00 & 11.80 & 0.16 & 22.80 & 22.90 \\
\hline $10 \%$ SM only & 7.00 & 0.09 & - & - & 13.05 & 0.18 & - & - \\
\hline Change (\%) & -43.80 & - & - & - & 10.60 & - & - & - \\
\hline $\begin{array}{c}\text { CW } \\
\text { as carbon } \\
\text { source } \\
\text { in } \\
\text { YFM medium } \\
\end{array}$ & 13.32 & 0.18 & 26.64 & 26.65 & 2.03 & 0.03 & 4.06 & 4.09 \\
\hline Change (\%) & 6.98 & - & - & - & -82.80 & - & - & - \\
\hline $\begin{array}{c}\text { SB as carbon } \\
\text { source } \\
\text { in } \\
\text { YFM medium }\end{array}$ & 15.80 & 0.22 & 31.60 & 35.90 & 4.50 & 0.06 & 9.00 & 9.03 \\
\hline Change (\%) & 26.90 & - & - & - & -61.90 & - & - & - \\
\hline $\begin{array}{c}\text { SD hydrolysate } \\
+ \\
\text { yeast extract }\end{array}$ & 16.50 & 0.23 & 33.00 & 33.00 & 4.97 & 0.05 & 9.94 & 9.98 \\
\hline Change (\%) & 32.50 & & & & -57.80 & - & - & - \\
\hline $\begin{array}{c}\mathrm{SBP} \\
+ \\
\left(\mathrm{NH}_{4}\right)_{2} \mathrm{SO}_{4} \\
\end{array}$ & 10.73 & 0.15 & 21.46 & 21.50 & 2.53 & 0.04 & 5.06 & 5.07 \\
\hline Change (\%) & -13.70 & - & - & - & -78.60 & - & - & - \\
\hline FJW & 17.20 & 0.24 & 37.30 & - & 19.90 & 0.28 & 37.40 & - \\
\hline Change (\%) & 38.15 & - & - & - & 68.60 & - & - & - \\
\hline
\end{tabular}


Comparing the bioethanol production by $\mathrm{Cl}$. Iusitaniae Gr45 and Sacch. cerevisiae B1 on YFM medium with that obtained by the tested agro-industrial byproducts (Table 14), it could be noticed that the bioethanol production by the first strain increased about $6.98,26.9$ and $32.5 \%$ by using CW, SB as carbon source on YFM medium and sawdu SD st hydrolyzate containing yeast extract (as nitrogen source) treatments, respectively and decreased by about $43.8 \%$ at $10 \%$ SM treatment whereas the later treatment increased the bioethanol production by the second strain about $10.6 \%$. Using SBP hydrolyzate containing $\left(\mathrm{NH}_{4}\right)_{2} \mathrm{SO}_{4}$ gave a drastic effect on bioethanol production by both tested strains, whereas using FJW at 130 and $150 \mathrm{mll}^{-1}$ led to increase the bioethanol production by Cl. Iusitaniae Gr45 and Sacch. cerevisiae B1 about 38 and $68 \%$, respectively. So, it could be stated that using FJW was the best agro-industrial waste material for bioethanol production by Sacch. cerevisiae B1and Cl. Iusitaniae Gr45 after 3 days incubation period at $30^{\circ} \mathrm{C}$ using static batch culture technique.

\section{CONCLUSION}

Bioethanol production by $\mathrm{Cl}$. Iusitaniae Gr45 increased about 6.98, 26.9 and $32.5 \%$ on CW, SB as carbon source instead of glucose on YFM medium and SD hydrolyzate containing yeast extract (as nitrogen source) treatments, respectively. Whereas, the later treatment increased the bioethanol production by Sacch. cerevisiae B1 to about $10.6 \%$. Whereas, the FJW at 130 and $150 \mathrm{mll}^{-1}$ recorded the highest bioethanol production by $\mathrm{Cl}$. Iusitaniae $\mathrm{Gr} 45$ and Sacch. cerevisiae B1 which increased by about 38 and $68 \%$, respectively comparing to production on YFM medium (control). So, it could be deduced that FJW was the best agro-industrial byproduct for bioethanol production by Sacch. cerevisiae B1 and Cl. Iusitaniae Gr45 after 3 days incubation period at $30^{\circ} \mathrm{C}$ using static batch culture technique. Further studies are needed to increase the efficiency of using the other agro-industrial byproduct for bioethanol production.

\section{REFERENCES}

1. Banat, I.M. and R. Marchant. 1995. Characterization and potential industrial applications of five novel, thermotolerant, fermentative, yeast strains. World J. Microbiol. Biotechnol. 11: 304-306.

2. Bettiga, M., O. Bengtsson, B. Hahn-Hagerdal and M.F. Gorwa-Grauslund. 2009. Arabinose and xylose fermentation by recombinant Saccharomyces cerevisiae expressing a fungal pentose utilization pathway. Microb Cell Fact, 8, p. 40. 
3. Dhillon, G.S., K. Surinder, and K.B. Satinder. 2013. Perspective of apple processing wastes as low-cost substrates for bioproduction of high value products: A review. Renewable Sustain. Energy Rev. 27: 789-805.

4. Ergun, M. and S.F. Mutlu. 2000. Application of a statistical technique to the production of ethanol from sugar beet molasses by Saccharomyces cerevisiae. Bioresour. Technol. 73: 251-255.

5. Flood, A.E. and C.A. Preistly. 1973. Two improved methods for the determination of soluble carbohydrates, Ferri-cyande Arsenomolybdate method. J. Sci. Fd. Agric. 24: 949-959.

6. Forster, J. 2001. Data Analysis using SPSS for windows versions 8-10. Sage publication Ltd., London.

7. Freer S.N., and R.V. Greene. 1990. Transport of Glucose and Cellobiose by Candida wickerhamii and Clavispora lusitaniae. J Biol Chem., Vol. 265, 22, 1286412868.

8. Gamal, Rawia, F. Nasser, R.. Fatma, Abdelhady M. Hemmat and M. El-Sawy. 1991. Glycerol production by osmotolerant yeast strain using fermentor as fed batch and continuous culture techniques. Annal. Agric. Ain Shams Univ. 36: 319321.

9. Ge, J.P., B.Y. Cai, G.M. Liu, H.Z. Ling, B.Z. Fang, G. Song, X.F. Yang, and W.X. Ping. 2011. Comparison of different detoxification methods for corncob hemicelluose hydrolysate to improve ethanol production by Candida shehatae ACCC 20335. Afr. J. Microbiol. Res. 10: 1163-1168.

10. Gubicza Krisztina, U.N. Ismael, F. Csaba, T. Zhuoli, O.I. Lonnie and B. Zsolt. 2014. Techno-economic analysis of ethanol production from sugar cane bagasse at the Stan Mayfield Biorefinery. 36th Symposium on Biotechnology for Fuels and Chemicals.

11. Jackson, M.L. 1973. Soil chemical analysis. Pientice Hall of india. Private, New Delhi 183-192.

12. Jeffries, T.W. and Y. Jin. 2000. Ethanol and thermotolerance in the bioconversion of xylose by yeasts. Adv. Appl. Microbiol. 47: 221-268.

13. Keshwani, D.R. and J.J. Cheng. 2009. Switch grass for bioethanol and other value-added applications: a review. Bioresour. Technol., Vol. 100, 4:1515-23

14. Lau, O.W. and S.F. Luk. 1994. Spectrophotometric method for the determination of ethanol in beverages and beer samples using cerium (IV) as reagent. Int. J. food sci. Technol. 29: 469-472. 
15. Liang, L., Y. Zhang, L. Zhang, M. Zhu, L. Shi-Zhong and L. Yu-nan. 2008. Study of sugar cane pieces as yeasts supports for ethanol production from sugar cane juice and molasses. J. Ind. Microbiol. Biotechnol. 35: 1605-1613.

16. Lin, Y. and S. Tanaka 2006. Ethanol fermentation from biomass resources: current state and prospects. Appl. Microbiol. Biotechnol. 69: 627-642.

17. Phitsuwan, P., K. Sakka and K. Ratanakhanokchai. 2013. Improvement of lignocellulosic biomass in planta: A review of feedstocks, biomass recalcitrance, and strategic manipulation of ideal plants designed for ethanol production and processability. Biomass Bioenergy 58: 390-405.

18. Ramadan, E.M., M. El-Sawy, Gamal F. Rawia and Abdelhady M. Hemmat. 1985. Growth parameters of yeast grown on agricultural residues using shake flasks as a batch culture. Annal. Agric. Sci. Fac. Agric. Ain Shams Univ. 30: 25-45.

19. Rao, R.S., B. Bhadra and S., Shivaji 2008. Isolation and characterization of ethanol-producing yeasts from fruits and tree barks .Lett. Applied Microbiol. Vol. 47, 1: 19-24.

20. Renó, M.L.G., E.E.S. Lora, J.C.E. Palacio, O.J. Venturini, J. Buchgeister and O.A. Almazan. 2011. LCA (life cycle assessment) of the methanol production from sugar cane bagasse. Energy, Vol. 36:3716-26.

21. Rodriguez, L.A., M.E. Toro, F. Vazquez, M.L. Cerrea-Daneri, S.C. Gouiric and M.D. Vallejo. 2010. Bioethanol production from grape and sugar beet pomaces by solid-state fermentation. Int. J. Hydrogen Energy 35: 5914-5917.

22. Takeshige, K. and K. Ouchi. 1995. Factors Affecting the ethanol productivity of yeast in molasses. J. ferm. Bioeng. 79: 449-452.

23. Vučurović, V.M. and R.N. Razmovski. 2012. Sugar beet pulp as support for Saccharomyces cerivisiae immobilization in bioethanol production. Industrial Crops and Products, Vol. 39: 128-134.

24. Yan, X., O.R. Inderwildi, D.A. King and A.M. Boies. 2013. Effects of ethanol on vehicle energy efficiency and implications on ethanol life-cycle greenhouse gas analysis. Environ Sci Technol., Vol. 47, 11:5535-44.

25. Young, D.S. and R.B. Friedman. 2001. Effects of disease on clinical Lab. Tests, 4th ed AACC. 


\section{التحويل الحيوي لبعض المخلفات الزراعية و مخلفات التصنيع الزراعي إلى الإيثانول الحيوى بواسطة الخمائر المحلية في البيئات الثابتة \\ طارق سعيد الطيب'، همت محمد عبد الهادى'، عماد عبد العزيز سالم"، ابتسام زكريا عبد العال"

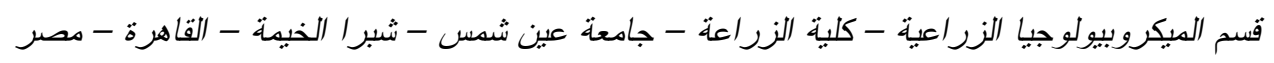

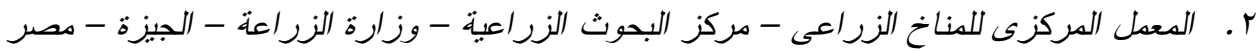

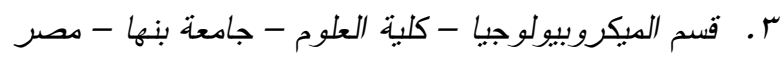

تم اختبار بعض المخلفات الزر اعية و الصناعية (مولاس قصب السكر ، قوالح الذرة ،

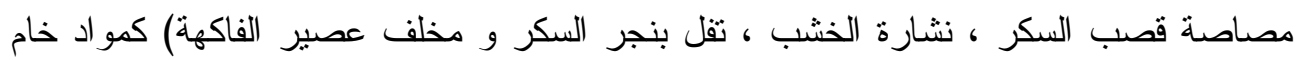

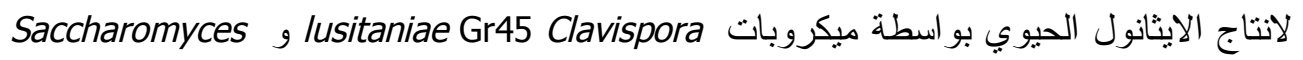

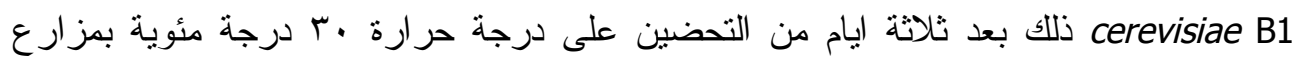

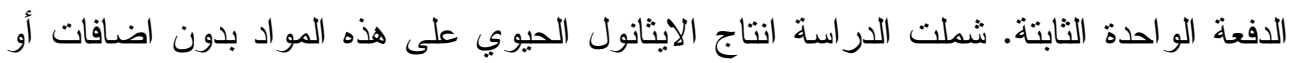
باضافة مصادر نيتروجين (سلفات أمونيوم او مستخلص خميرة). أعلى انتاج من الانئن الايثانول

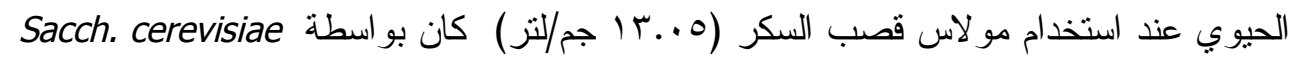

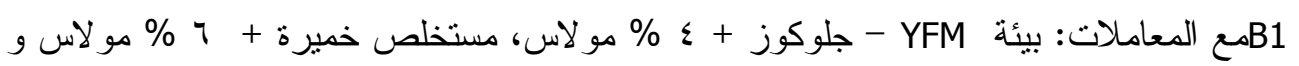

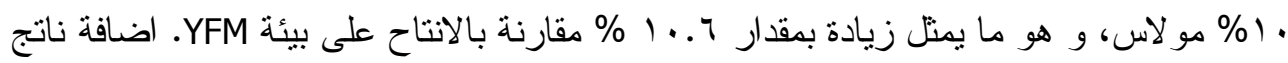

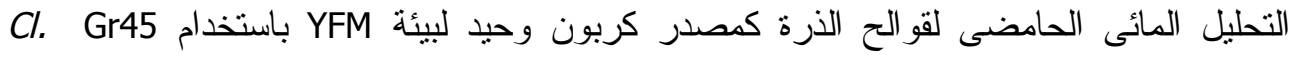

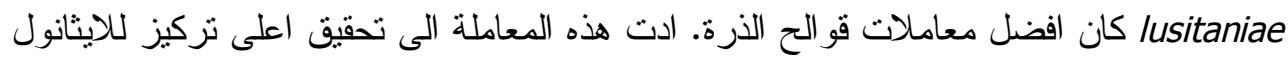

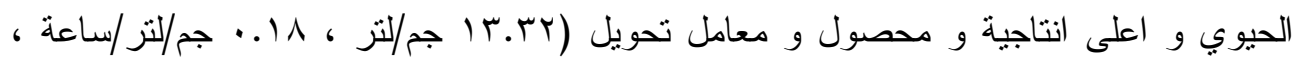

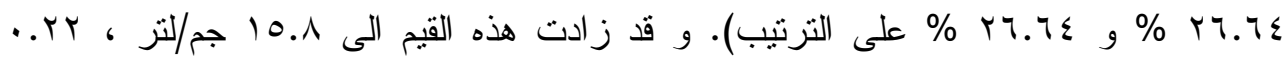

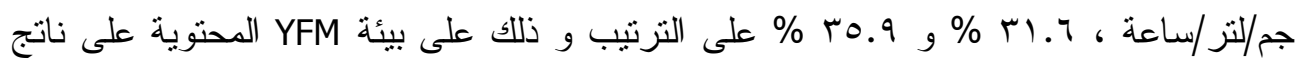

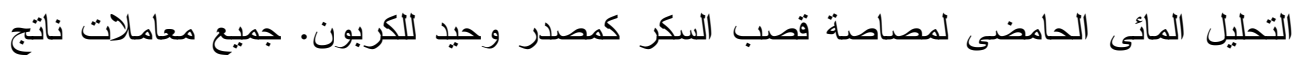

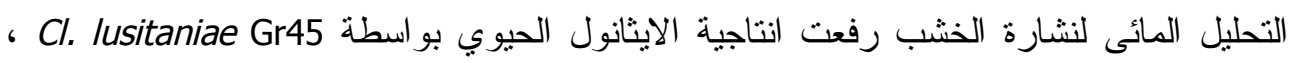

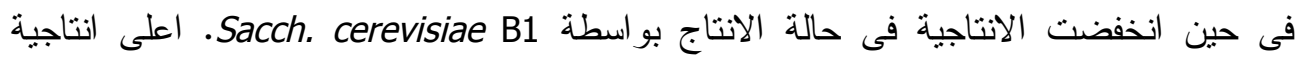

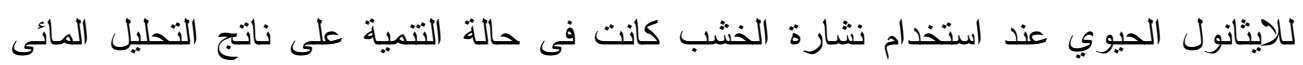

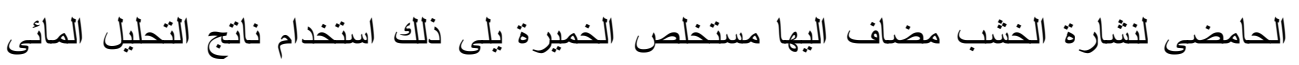

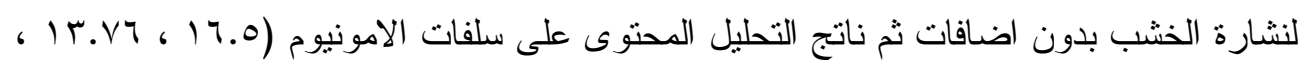

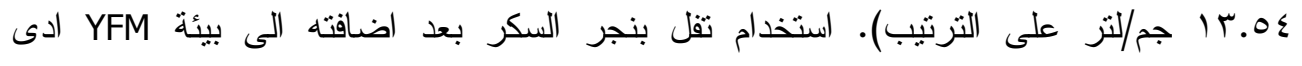

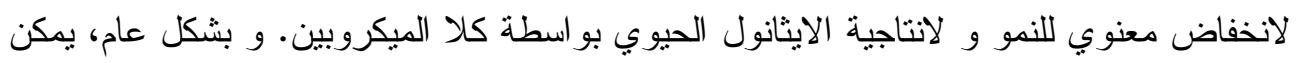

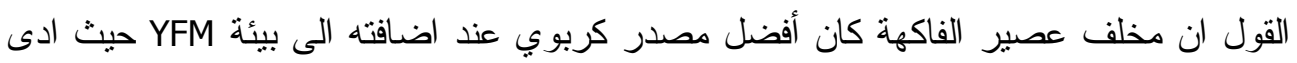

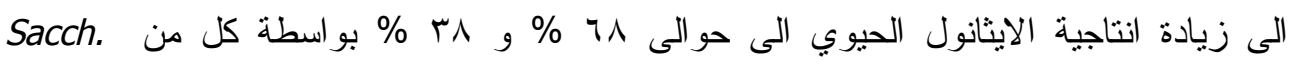
cerevisiae B1 